\title{
Equity and Digital Literacies: Issues of Access, Ethics and Engagement in a Youth Community Setting
}

\author{
COLIN ANDREW FORD \\ Media Programs Facilitator of Directions Youth Services Centre
}

\begin{abstract}
This article reports on the issue of confidentiality faced by a community youth agency that provides access to digital technology for homeless or street-involved youth. Social media is the prevalent form of communication in displaced communities and presents certain ethical challenges as a result of creating and sharing media with potential unintended audiences. Ensuring ethical practices is a key aspect of the ongoing process of developing digital literacy that changes as technology evolves. It requires the facilitator's focused attention to guide the youth in their ability to consider their digital footprint and potential unintended consequences of their practices.
\end{abstract}

\section{Keywords}

digital literacy, homeless youth, digital ethics, confidentiality, technology, social media, digital footprint

Two Guitars and Two Red Plastic Chairs: The Evolution of the "Media Program"

Sometimes a guitar becomes more than a guitar in the relationship between the teacher and a student. Like a bar between a patron and bartender, it becomes a conduit of anonymous communication, without judgment or consequence. I used to work as a sales manager for a large Canadian musical instrument retailer. I oversaw guitar, drum, recording and keyboard sales with a staff of four people. The store was located on Richards and Hastings Street in Vancouver. As a result, we had a lot of clientele from the Downtown Eastside, which is a catchment area for homeless and poorly housed people dealing with addiction, the sex trade, and mental health issues.

One hot, July afternoon I noticed a young customer looking a little worse for wear in his tattered, black leather jacket sitting on a stool beside the guitar wall. He appeared to be having the time of his life playing away on an electric guitar. His musical ability seemed pretty rudimentary, but it didn't appear to faze him. He was just having fun. I then noticed one of my staff members staring at him with disgust. She turned to me and asked: "Should I ask him to put the guitar back?”

"Why?” I replied, "He seems to be enjoying himself."

"Well... Obviously, he can't afford it."

“That’s a \$3000 Gibson Les Paul,” I told my misguided employee. “Not many people can afford that guitar."

She muttered something under her breath, turned around, and retreated to her duties as the waft of discordancy continued from the expensive tobacco-coloured Gibson Les Paul guitar. 
At this point, I started to listen more intently to the young man in the black leather jacket as he struggled through one chord to the next. I went over and asked if I could teach him a chord or two. He excitedly handed me the guitar and said: "Yes! Yes please! I can't afford guitar lessons. I'm homeless, and I'm on income assistance. The music books are too hard to understand." I showed him a couple of chords and he eagerly absorbed them. He happily went back to playing with his new-found knowledge and confidence. This experience was life-changing as I saw a great potential to make a difference in the community using my knowledge of the guitar. I thought to myself: "I work in a large store with plenty of offices and guitars that I can use, and I taught guitar most of my adult life. Why not reach out to the community, use those resources and teach for free on my lunch hour? Why not? There is obviously a need.”

I started by contacting a number of youth agencies with my offer. Initially, it seemed like I banged my head against a wall of indifference. Although I felt frustrated, I persisted, and it eventually paid off. One day, I received a phone call from a youth agency. They had heard about my offer through another agency and were eager to bring along as many street youth as I could handle for guitar lessons.

Fast forward to six weeks later. I found myself surrounded by 15 youth and the program's youth facilitator learning to play guitar. That day, everyone left equipped with a couple of chords and a little proud smirk. I felt fantastic! I made a bunch of youth happy, and all it took was the desire to make a difference and the time to do so.

Several months later I started volunteering at Directions Youth Services (DYS), a division of Family Services of Greater Vancouver that provides Vancouver's homeless youth and youth at-risk from thirteen to twenty-four years of age with a single-entry point to access the tools, support, and guidance they need to go about making healthy, positive changes in their lives. I taught in a large, abandoned, sterile community room with two red plastic chairs and two guitars that I had donated. Initially, I spent long hours sitting in the middle of the community room on one of the plastic chairs, staring at the open door and shouting out to the youth as they passed by the room: "Hey! Do you want to learn how to play guitar?” Sometimes, they ignored me; other times they were curious and came in. Eventually, the room started to fill up, and I needed more equipment. I raised money to buy more gear by using my connections through the music industry and corporate partnerships. With increased attendance, I decided to move into a larger room with more possibilities to accommodate future expansion. By developing corporate capital donations and partnering with video game giant, Electronic Arts (EA) and their Outreach \& Corporate Giving Manager, Wendell Harlow, I was able to expand my program even further. EA helped propel access to technology in the media room to a new level. Our partnership continues to this day.

Now, 12 years later as the "Media Program" Coordinator for DYS, I run a 1,000square foot facility that proudly promotes arts engagement, inclusion and esteem building. The "Media Program" is constantly evolving and the media room is currently equipped with a fully functional recording studio, iMac workstations, state-of-the-art gaming consoles, large flat-screen TVs, guitars, basses, drums, mandolins, DJ tables and pianos. The program provides theatre, music, computer and film training. Over the years, through trial and error, I have boiled down the "Media Program" to the following philosophy: "Arts \& technology engage self-expression. Expression is a vehicle to confidence. Confidence is key for making positive choices in life moving forward.” 
An important component of the "Media Program" is the "Another Slice" website (http://anotherslice.ca). The concept for "Another Slice” was inspired by a street magazine called "The Slice”. The 'zine was originally conceived in the 90's by youth worker, Wendy Wood while she worked at The Gathering Place Community Centre, which is run by the City of Vancouver and offers programs and services to vulnerable populations in Downtown South community. The title of the 'zine "The Slice" came from Wendy's ingenious method of bribing prospective homeless clients with slices of pizza to encourage them to contribute their art and poetry to the publication. It has been read all over the world. In the late 90's, Leonard Cohen read a passage from it on stage during one of his performances at the Orpheum Theatre. I began facilitating "The Slice" in 2006 and eventually converted it into a website - anotherslice.ca. "Another Slice" became the foundation for every project that we do in the media room to this day. The website documents all of the activities and creative projects that evolve from the Media Program and serves as a way to empower youth's voices through weekly blogging, art, sharing their music recordings and poetry.

A few years ago, I invited the youth at DYS to participate in "Another Slice University" (ASU) project (Ford, 2012). The launch of iTunes University (iTunes U) in 2007 offering free educational content on iTunes' store, served as an inspiration for ASU. I decided to approach Dr. Theresa Rogers, Professor at the University of British Columbia (UBC), who had worked with the 'zine group a few years prior, and ask her to support a youth-led educational initiative that would provide accessible, entertaining, short, online video episodes for the general public about the challenges of youth homelessness. As a result of this partnership, six educational videos on topics like street resources for the homeless and the history of methamphetamines were released on iTunes U (Ford, 2012). With our support, the youth wrote, directed and edited their own short films as they learned about digital literacy and the art of filmmaking. All the videos were screened at Pacific Cinematheque theatre in Vancouver to a very receptive audience (see also Rogers, Schroeter, Wager, \& Hague, 2014).

\section{Digital Literacy and Access Among the Youth}

Based on my observations, there seems to be a general perception that streetinvolved, at-risk and homeless youth aren't technology savvy and don't have access to technology. If they do, it's seen as a needless opulence (McInnes, Li, \& Hogan, 2013). During my daily interactions with youth, I noticed that they possess a high level of technology literacy. They have access to and use the Internet, and mobile technologies and social media is a big part of their lives (McInnes et al., 2013). For youth, technology is an organic means of keeping in touch with friends and family. Often, their survival depends on access to technology for connecting to outside resources such as housing, income assistance, health care, medical emergencies, personal supports and counselling. In their study about homeless drug users and technology, Neale and Stevenson (2014) noted that it is vital for homeless individuals to have access to information technologies: "A number of individuals described panicking at the thought of technology failing as this would cut them off from others and leave them feeling isolated" (p. 1469). Sometimes, clients will use their mobile phones as a status symbol to conceal their homelessness and appear like someone who has a stable lifestyle (McInnes et al., 2013). 


\section{Ethical Implications of Digital Evolution}

As the "Media Program" coordinator, I struggle with the ethical implications of digital evolution and rapid technological development over the last decade, such as our clients' digital footprint - the permanent digital footprint of all their web practices that can have a negative impact in their future. When the program started in 2005, social media as we know it did not exist. Facebook had just been launched about a year earlier and issues of real-time privacy and surveillance were yet to expand into practically every area of our lives.

Our clientele has a youth confidentiality agreement with DYS. The centre provides respite from the challenges and politics of street life for clients that access DYS. It is a place where a youth can be a youth. No judgment. It is a place of healing and support. However, when I am met with the challenges of youth's access to modern technology, the potential for breach of confidentiality is ever increasing. It's a battle I fight on a daily basis. Do I allow youth to access unsavoury websites? Where is that line drawn? YouTube? Craigslist? Think about it. Think about all the potential breaches of confidentiality and general safety concerns. There are a few questions that I always adhere to in case of indecision: Where are our clients going to be five years from now? 10? Will their digital footprint hinder them, if and when they become, say, the CEO of a multinational corporation? What is the best way to inform clients about the perils, potential risks, and the consequences of poor social media decisions?

As a facilitator, I must always be aware of how technology is used and if it is being applied in safe practice. One afternoon in the media room I noticed one of our volunteers, Henry, chatting with a new client. Henry had been working with me for about a month and had an infectious enthusiasm for volunteering that made him popular. The client wanted to take a picture of herself on one of the computers in the media room to update her profile photo on Facebook and show off her new purple-highlighted hair to her online friends. The purple-highlighted youth asked Henry to help her take the best photo of herself on the computer. He eagerly explained that all iMac computers in the media room have the capacity to take photos with an application called "Photobooth." Then, he demonstrated to this youth how to use the application and set the photo timer to go off in three seconds. She posed, highlighting her new highlights. One. Two. Three. In that moment, another youth walked into frame behind our purple-highlighted fashionista. Unbeknownst to this youth in the background, they now appeared in a photo that could be potentially shared with hundreds of other online users. As a result, the youth who now found themselves in the background of a selfie can now be recognized by many of their mutual "friends" that have accounts on Facebook. I observed what had transpired and asked the first young woman to take another photo because of the breach of confidentiality in the previous photo. To this day all computers in the media room have their cameras deactivated to avoid the possibility of misuse.

When working with any demographic that relies on your judgment for their own safety, you must always ask yourself: "What is the worst possible result that can happen from anything you say yes to?” By agreeing to help a youth take a photo in the media room, Henry should be aware that he might create a situation where one or several youth's confidentiality is breached. As one of the supervisors at DYS often says: "What is the intended and what is the unintended?" Here is how the situation described above could have played out in the worst case, unintended scenario. When the youth who unwittingly 
stepped into the background of the photo is recognized by some of their "friends," they are surprised because this youth has an outstanding debt to a gang-affiliated friend and is not supposed to be in Vancouver. This youth, who did not intend to be in a photo, is now in a great deal of danger when they leave the centre. As program coordinator, it is my obligation to educate the youth about privacy and confidentiality. I encouraged the youth to be aware of who appears in their photos and to make sure that the people who appear in those photos have expressed their consent.

The Struggle Between Access and Ethics

When it comes to digital literacy, sometimes there isn't a clear-cut answer to balancing ethics and access. A simple YouTube video can have grave consequences. Youth frequently watch videos on one of the 21.5” iMac computers in the media room. One afternoon I noticed that the youth were watching a popular hip-hop video. In that video, the famous artist sat back in a very large, metal chair and "spat rhymes" about friends, cars, and money. While the video played, one of my coworkers dropped by the media room and proceeded to talk to one of our other clients about their upcoming housing appointment. After their discussion, she came over to my desk, leaned over and quietly asked: "Colin, do you think that the video he is watching is appropriate for the Media Program?" A bit baffled, I glanced back at the video on the 21.5” iMac screen and saw a young woman in a very skimpy, short black dress, provocatively gyrating to the beat of the popular hip-hop tune. Pretty tame stuff by hip-hop culture standards, but what are the unintended consequences? That video could unintentionally trigger post-traumatic stress for another youth in the room who had been sexually abused or involved in the sex trade. Do we ask the youth to shut it off? Do we ban hip-hop videos from the Media Program forever? Are we being overly vigilant? Where is the line drawn?

As technology evolves, so must the facilitator. It is no longer viable to be anywhere other than ahead of the technological curve and at the forefront of social media evolution. Technology evolves faster and faster each year and the lines between personal privacy and public domain, as well as digital and real life become blurred or even invisible. Technology is no longer a neutral means of delivering information (Buckingham, 2015). In the words of Umberto Eco: "If you want to use television to teach somebody, you must first teach them how to use television" (as cited in Buckingham, 2015, p. 263). It is important to equip the user with an understanding of how technology works, its applications and possible repercussions. I am working with a pronounced, marginalized community that relies on good judgment from the staff at DYS to keep them educated and aware of unintended technological consequences of their actions. As any other youth, marginalized youth search for acceptance, a sense of self and understanding about the world around them and the online world becomes an important platform where they can communicate, participate and feel accepted. The complexities of being homeless, at-risk or street-involved compound the potential unintended negative outcomes of uninformed social media interactions which become a critical ethical challenge for any resource that provides digital access as part of their community engagement.

We live in an era of unparalleled technological growth and wonderment. The future of technological advancement is difficult to predict because of the current rate of its exponential expansion. It has the potential to transcend every single aspect of human life. Based on my experience, educating youth about the ramifications of poor social media 
habits is not always enough, because they often have the perception that virtual reality is indeed virtual and it doesn't have any real-world consequences. For example, for some of my clients Global Positioning Systems or GPS, is just an acronym for being somewhere on a map that Snapchat, Facebook, Instagram and Twitter can find and not their real-time location. There is also a bravado that exists behind the digital word. When someone questions a person who exhibits cyber bullying and other negative tendencies in their behaviour, one the most common responses is that they were just joking; to them, words in a digital message do not have the same weight as in the real-time verbal expression.

The technology facilitator has to be aware that the concept of privacy changes as each new generation goes online. In my opinion, technological advances are not born out of necessity, but out of the desire for convenience. Convenience chips away at privacy until the concept of privacy mutates to match the convenience. As an example, facial recognition and thumb imprint technology that have been used for decades by law enforcement to privately imprint and identify our uniqueness are now the mainstream identification methods for us to unlock our phones.

The future of youth work facilitation should empower clients with digital literacy, so that they are better prepared to use technology wisely. Youth who grasp the basics of digital literacy, social media, and online educational resources will have a better opportunity to control many aspects of their lives that are influenced by technology as well as their digital footprint in this brave new world.

\section{References}

Buckingham, D. (2015). Defining digital literacy—what do young people need to know about digital media? Nordic Journal of Digital Literacy 1(4), 21-35.

Ford, C. [AnotherSlicedotCA]. (2012, June 7). Another Slice University. [Video file]. Retrieved from http://bit.ly/2lCbGuq

McInnes, D. K., Li, A. E., \& Hogan, T. P. (2013). Opportunities for engaging lowincome, vulnerable populations in health care: A systematic review of homeless persons' access to and use of information technologies. American Journal of Public Health, 103(2), 11-24.

Neale, J., \& Stevenson, C. (2014). Homeless drug users and information technology: A qualitative study with potential implications for recovery from drug dependence. Substance Use \& Misuse, 49(11), 1465-1472.

Rogers, T., Schroeter, S., Wager, A. \& Hague, C. (2014). Public pedagogies of streetentrenched youth: New literacies, identity and social critique. In K. Sanford, T. Rogers, \& M. Kendrick (Eds.), Everyday Youth Literacies: Critical Perspectives for New Times, (pp. 47-61). Singapore: Springer. 